\title{
"CONSTRUTOR DE ESPELHOS": ETNOGRAFIA, LITERATURA E MÍSTICA NA OBRA DE MICHEL LEIRIS (FRANÇA, 1930-1960)
}

\author{
"THE MIRROR MAKER": ETHNOGRAPHY, LITERATURE \\ AND MYSTIQUE IN THE WORKS OF MICHEL LEIRIS \\ (FRANCE 1930-1960)
}

Gabriela Mitidieri Theophilo*

\begin{abstract}
Resumo: Este artigo pretende expor uma análise de alguns textos e conferências do escritor e etnólogo francês Michel Leiris (1901-1990). Tais textos versavam sobre etnografia e literatura e foram escritos, ou pronunciados, em diferentes datas nos anos posteriores à sua volta da missão Dakar-Djibouti (primeira grande missão etnográfica francesa em territórios coloniais africanos, da qual Leiris participou como secretário-arquivista) e à sua profissionalização como etnógrafo, abarcando, portanto, as décadas de 1930 à 1960. Por meio dos argumentos neles contidos é possível demonstrar como Leiris concebeu, ao longo deste tempo, as formas possíveis de produção de conhecimento sobre si mesmo e sobre o outro, os modos possíveis (e a importância) de se aprender com o outro "não ocidental" e, enfim, as possibilidades de transmissão desses saberes. Tendo vivido quase todo o século XX, Leiris esteve envolvido em importantes debates no âmbito das artes e das humanidades europeias. Sua obra dialogou com aquelas de intelectuais que exerceram contundentes críticas à modernidade, opondo-se à ideia de homo economicus e ao suposto excesso de racionalismo e de tecnicismo ocidentais. Apropriando-se de preceptivas da mística e do neoplatonismo dos séculos XV e XVI, ele desenvolveu uma concepção de etnografia que priorizava o contato e a identificação, buscando o que havia de comum entre todos os homens - ainda que com respeito às diferenças culturais..
\end{abstract}

Palavras-chave: Michel Leiris, etnografia, mística. 


\begin{abstract}
This article focus on the analysis of some texts and lectures made by the French writer and ethnologist Michel Leiris (1901 - 1990). These writings on ethnography and literature have been written or uttered in different occasions after his return from the Dakar-Djibouti mission (the first large-scale French ethnographical mission on African colonial territories, where Leiris took part as secretary-archivist) and his professionalization as an ethnographer, therefor, through the decades of 1930 and 1960. By analyzing the arguments drawn on its papers and lectures, it is possible to evince how Leiris conceived the possible forms of knowledge about the self and the other, the possible ways (and the importance) on learning with the "non-westerner" other and the possibilities of transmitting this knowledge. As he has lived through almost all of the twentieth century, he was involved into important debates on European art and humanities. His works are part of the intellectual critique on modernity, opposing the idea of a homo economicus and the perceived excessive focus on rationality and technicality of the western world. By using precepts of the mystique and neo-Platonic thought of the XV and XVI centuries, he developed a conception of ethnography that prioritizes contact and identification, looking for what was common to every men - but always aware and respectful of their cultural differences.
\end{abstract}

Keywords: Michel Leiris, ethnography, mystique.

* Doutoranda em história pela UFRJ, e-mail: gabitheophilo@gmail.com.br 


\section{Considerações iniciais}

No ano de 1931, o Estado francês promoveu a primeira grande missão etnográfica em seus territórios coloniais no continente africano. Conhecida como missão Dakar-Dijbouti, essa expedição tinha por objetivo a produção de conhecimento sobre os povos colonizados e, sobretudo, a coleta de materiais para os museus franceses. O escritor Michel Leiris fora convidado pelo etnólogo Marcel Griaule ${ }^{1}$ para o cargo de secretário-arquivista da expedição, e seu papel seria o de registrar a viagem, narrando os principais acontecimentos, catalogando os objetos recolhidos e descrevendo os costumes dos povos visitados. Até então, Leiris havia atuado como poeta, participado dos debates empreendidos pelo grupo surrealista - nos moldes estabelecidos por André Breton $^{2}$ - e, entre os anos de 1929 e 1930, após seu rompimento com Breton, participara da revista de etnografia Documents ${ }^{3}$, ao lado do também escritor e amigo Georges Bataille.

Foi a partir de sua participação nas discussões promovidas pelo grupo surrealista que Leiris teve os primeiros contatos com alguns dos assuntos que lhe seriam caros ao longo da vida, como aqueles relativos à arte africana - dita "arte primitiva" - à psicanálise e ao "esoterismo" (este embasado, sobretudo, na mística cristã renascentista e nos textos de filosofia neoplatônica do mesmo período). ${ }^{4} \mathrm{Na}$ revista Documents, por sua vez, ele teve a oportunidade de aprofundar-se em debates prementes à época na França, que interligavam etnografia, museologia e artes. Foi em Documents que ele escreveu os primeiros textos voltados para o tema da etnografia (embora tenha abordado muitos outros assuntos também), e, por meio da participação na revista, conheceu o etnólogo Griaule.

Entre maio de 1931 e fevereiro de 1933, como membro da expedição Dakar-Djibouti, Leiris percorreu a África do Senegal à Etiópia, compreendendo as chamadas África Equatorial Francesa (AEF) e África Ocidental Francesa (AOF). O resultado de seu trabalho foi um volumoso livro no qual ele não só expos o cotidiano da viagem como também anotou suas impressões íntimas, seus sentimentos e praticou o que se poderia chamar de uma meta-etnografia, questionando os limites da recém constituída disciplina e denunciando o autoritarismo de certas práticas dos funcionários coloniais e dos estudiosos da missão - ele mesmo incluído. O livro, intitulado África fantasma, foi publicado no ano de 1934 e lhe rendeu a inimizade de Marcel Mauss e do próprio Marcel Griaule, que temiam que aquela narrativa ameaçasse o futuro da disciplina na França. ${ }^{5}$

A viagem à África pode ser considerada como iniciática na vida de Leiris. Nas duas décadas posteriores ele iria frequentar os cursos do Instituto de Etnologia e conquistar seus diplomas na área. ${ }^{6}$ Além disso, iria consolidar e amadurecer - a partir de um exercício constante de autoquestionamento suas concepções acerca da literatura e da etnografia, práticas que lhe eram caras e sobre as quais ele fundamentaria a própria existência. Pode-se dizer 
que a escrita literária (especialmente a chamada "escrita de si") e as reflexões etnográficas associavam-se, para ele, a uma posição de permanente crítica e desconfiança em relação à sociedade ocidental (e às suas relações com outras sociedades) e à construção de uma ética específica, como se verá.

Como já foi dito, um dos temas sobre os quais Leiris se debruçou foi o da mística. Tal qual para muitos outros artistas e intelectuais do início do século $\mathrm{XX}$, o estudo das preceptivas "esotéricas" ou místicas - contidas, sobretudo, em textos da filosofia neoplatônica e no corpus hermético - revelavam-se como possíveis modelos para se repensar as relações do homem com o mundo e com os saberes. Os estudos da mística tornavam-se, assim, uma fonte de argumentos contra um suposto "divórcio fundamental entre homem e mundo", contra o homo economicus e contra o excesso de tecnicismo e racionalismo ocidentais. A chamada "teoria das correspondências", caracterizada por um tipo de produção de conhecimento feito por meio de um sistema de analogias entre todas as coisas - associada a certo Orientalismo (um orientalismo difuso que, em alguns casos, como entre os escritores surrealistas, se definia por uma atitude hostil a tudo que fosse considerado "ocidental") ${ }^{8}$ - era vista, então, ao mesmo tempo como uma potência heurística, de fato, e como uma alternativa para que o homem pudesse libertar-se das amarras instituídas por um racionalismo científico, tal como desenvolvido ao longo dos séculos XVIII e XIX.

Segundo Maria Lucia Dal Farra9 ${ }^{9}$, ao longo de toda a década de 1930 as remissões de André Breton, por exemplo, aos textos herméticos, à cabala, ao tarô, ao "ocultismo" e à alquimia, de modo geral, seriam abundantes. Posteriormente, ele exerceria, inclusive, um certo tipo de militância em favor da importância da "aproximação do esoterismo à arte e à poesia". Até mesmo os escritores eleitos como "precursores" do surrealismo (entre outros, Baudelaire, Rimbaud e Mallarmé) foram colocados por ele numa tradição que valorizava a "infiltração da matéria esotérica na obra artística". Isso fazia parte do entendimento do processo poético como uma "operação alquímica". Walter Benjamin, no texto Le surréalisme, mythe et violence, afirmara que os jogos poéticos surrealistas eram, mais do que brincadeiras artísticas, "experiências mágicas sobre as palavras". ${ }^{10}$ De fato, no ano de 1954 , em texto escrito para a revista Médium, ao explicar o funcionamento de um dos últimos jogos do surrealismo, denominado L'un dans l'autre, Breton assegurava que descrever uma coisa a partir de outra (procedimento do jogo), tinha o mérito de "retirar das palavras a descoloração causada pela sua função de troca elementar", além de revelar relações analógicas antes ocultas. Ele dizia, por fim, que esse fenômeno era originário da "teoria das correspondências ocultistas". ${ }^{11}$ Os jogos de metáforas e analogias tinham, nesse sentido, força heurística, concebidos como um modo de se gerar um "novo real".

Percebe-se, portanto, que toda a importância dada pelos surrealistas aos jogos de analogias e de metáforas estava imbuída de uma concepção 
mística, numa apropriação muito particular do corpus hermético e dos textos neoplatônicos. Havia a pretensão de que essas analogias fossem expandidas até a dissolução da própria identidade. A partir do momento em que o "eu" pudesse confundir-se com o "outro" e com a própria poesia, a "operação alquímica" seria bem sucedida. No ano de 1933, em texto escrito para a revista Le Surréalisme au service de la révolution, consagrado ao "Centenaire d'Arnim", Breton diria que "o eu-ele-mesmo' deve ser submetido ao mesmo regime que o objeto, à condição de que uma reserva formal venha abalar o 'eu sou'". 12

Em seu diário íntimo, em diversos dos textos escritos para a revista de etnografia Documents e, ainda, em artigos sobre diferentes temas escritos para periódicos de arte ou etnografia ao longo do século XX, Leiris versou sobre a ideia de "homem como microscosmo". Em Notes sur deux figures microcosmiques des XIV e XV siècles ${ }^{13}$, escrito para o primeiro número de Documents, em 1929, Leiris alinhava algumas de suas concepções às da cabala judaica (segundo ele, uma "mistura de ideias judaicas e cristãs conformadas pelo neoplatonismo") que consideravam o homem como correspondente ao universo, em todas as suas partes. $\mathrm{O}$ corpo humano seria uma miniatura do universo, assim como a alma humana, uma miniatura de Deus. Os iniciados na cabala, portanto, teriam formulado a tese da natureza microcósmica do homem, exposta de maneira clara, ainda de acordo com Leiris, nos escritos de Paracelso, por exemplo.

De acordo com Leiris, então, quase por toda parte - "não somente nas cabalas judaica e cristã, mas também entre os filósofos gregos e na maior parte das ciências ocultas" -, era possível encontrar esse modo de identificação, "verdadeiro sistema que partia do homem ao universo e, inversamente, do universo ao homem". Esse mecanismo responderia menos a motivos de ordem racional do que a uma vicissitude humana, a alguns dos desejos mais secretos e instintivos do homem, entre eles "o desejo do absoluto ou a busca do uno, projeção externa de seu polo interior". Se os sistemas de identificação por analogia representavam as forças instintivas do homem, portanto, para Leiris, muitos dos "enigmas em torno dos mais variados gestos e práticas humanos poderiam ser resolvidos se as ciências ocultas fossem consideradas como um espelho, refletindo essas grandes tendências". ${ }^{14}$

O entendimento da realidade para ele passava, então, pelo entendimento do homem e de seus instintos primeiros. Esses instintos, de acordo com os seus estudos, remetiam a relações de identificação com todas as coisas e à busca do uno, de modo que, se o verdadeiramente humano implicava relações de analogia entre todas as coisas e todos os seres, a realidade só poderia ser concebida em sua diversidade de formas e de relações.

Além dessas reflexões de cunho epistemológico - que, como no surrealismo, também resultaram em questionamentos no que dizia respeito às relações entre sujeito e objeto do conhecimento -, a ideia de que este 
operaria apenas por analogia e identificação o levou ao desenvolvimento de uma postura ética muito particular. Em diversas ocasiões Leiris afirmou que buscou a etnografia mais como uma forma de contato com o outro do que de conhecimento do outro. ${ }^{15}$ Ele via nas viagens uma das formas possíveis para a aquisição de um conhecimento "vivo e concreto", que não ficasse no âmbito da abstração. Ao longo de sua vida, Leiris buscou exemplos de manifestação do "homem total", expressão concebida por Marcel Mauss para designar o que ele considerava como "formas menos evoluídas de vida":

O estudo desse homem completo figura entre os mais urgentes daqueles que vos pedimos que façam. (...) É com ele que deparamos na história das massas e dos povos (...). Observais, em particular, a importância considerável do instinto no homem médio, mesmo em nossas sociedades modernas. (...) quanto mais recuamos em direção às formas menos evoluídas da vida social (...) tanto mais lidamos com homens instintivos, ou, se me permitis a expressão, eu preferiria dizer totais. Do mesmo modo, são esses homens que encontramos nas camadas mais amplas de nossa população (...). Com efeito, é somente o homem civilizado das elites de nossas civilizações e de um número pequeno de outras (...) que sabe controlar as diferentes esferas de sua consciência. (...) É especializado, em geral diferenciado hereditariamente pela divisão do trabalho social (...) Mas, sobretudo, ele está dividido em sua própria consciência, é um consciente..$^{16}$

Leiris teve aulas com Mauss no Instituto de Etnologia e certamente conhecia essa definição. Entretanto, para ele, o "homem total" era um modelo a ser seguido. O "homem civilizado", dividido, fragmentado, teria, portanto, algo a aprender com este "outro", que poderia ser encontrado em sociedades em que não havia separação entre as atividades do cotidiano e os aspectos intelectuais, religiosos, pedagógicos e lúdicos da cultura. Leiris também buscava essa totalidade em sua própria vida, especialmente através da escrita. Pode-se sugerir, assim, que toda a sua obra seria idealizada como uma unidade, uma busca incessante pela fusão entre vida, poesia e etnografia.

\section{Michel Leiris em busca do "Homem total"}

Em 17 de fevereiro do ano de 1933, os membros da missão DakarDjibouti retornavam a França. Leiris começaria, imediatamente, a trabalhar na exploração de suas anotações e do material coletado, tanto para a preparação de uma exposição que seria montada no Museu do Homem, 
quanto para o auxílio na composição do segundo número da revista Minotaure, inteiramente dedicado à expedição. ${ }^{17}$ Convidado por Paul Rivet, ele se tornaria responsável pelo departamento de África Negra do Musée du Trocadero. Ao longo dessa década, como já foi dito, ele obteve todos os seus diplomas na área de etnologia e traçou um planejamento para a escrita de seus estudos etnográficos - sobretudo a partir de suas experiências e pesquisas na viagem. Ao mesmo tempo, Leiris afirmava em seu diário o desejo de elaborar um projeto autobiográfico. Explicava que, naquele momento, não conseguia mais conceber outra forma literária possível que não fosse a "literatura de confissão". ${ }^{18}$

Em junho de 1935, Leiris escreveu um artigo para a revista Mer et autre mer, intitulado "L'Abyssinie intime". ${ }^{19}$ Nesse texto, diretamente impactado pelo período abissínio da missão Dakar-Djibouti, dissertava sobre sua própria concepção de viagem, especialmente no que dizia respeito a deslocamentos para regiões de culturas diferentes da do viajante.

De acordo com ele, o modo como se viajava costumava alterar sobremaneira a percepção que se poderia ter de um lugar ou de um povo. Viajantes turistas, por exemplo - que deveriam ser, ainda segundo ele, "soberanos flaneurs", mas que, frequentemente, não passavam "de vulgares pessoas apressadas" - jamais conseguiriam estabelecer uma relação de intimidade com as regiões pelas quais transitavam. Uma viagem verdadeira, portanto, não deveria seguir horários, calendário nem mesmo itinerário, configurando-se simplesmente como uma partida à aventura. Os possíveis incômodos ou percalços do caminho se constituiriam, por sua vez, como a "substância mesma de uma viagem", o "essencial de seu atrativo". ${ }^{20}$

De modo similar, deslocar-se num veículo moderno qualquer, separado da paisagem, "fechado numa construção movente" e "muito veloz para que seja possível questionar e observar", também não contribuía para a edificação de um conhecimento vivo e concreto, ou seja, existencialmente relevante. $\mathrm{Na}$ Abissínia, por exemplo, que conheceu mais profundamente como membro da missão Dakar-Djibouti, o ideal era locomover-se a cavalo - o que permitia deslocar-se mais rápido e confortável do que a pé e, ao mesmo tempo, deixava o viajante numa posição privilegiada para a visão, em contato com o sol e em meio à paisagem. ${ }^{21}$

Segundo ele, um viajante comum, via de regra, teria dificuldade de ver "por fora" daquilo que ele já esperava, condicionado por leituras anteriores. Para Leiris, era apenas por meio do "homem da rua", figura variada e dotada de particularidades individuais, que se poderia fazer uma ideia verdadeira de um lugar. Esse "elemento essencial que é a massa da população", entretanto, escapava totalmente ao viajante comum. ${ }^{22}$

No oposto, ao falar de si mesmo como um viajante que teve oportunidade de conversar de maneira mais próxima com muitas pessoas na Abissínia, afirmava: 
A despeito de pequenas incompatibilidades que podem irritar, ele descobriu toda uma intimidade, uma espécie de fraternidade, ou ao menos de sadia cordialidade, tanto é verdade que homens são sempre homens e que, por todo lugar onde se encontram, é simples entender-se com eles quando não há nenhuma razão material de conflito. ${ }^{23}$

Nesse ínterim, Leiris explicitava um posicionamento que marcaria todas as suas reflexões etnográficas, conferindo-lhes um tom diferenciado. A etnografia não era, para ele, uma disciplina da alteridade, da diferença radical, mas, sobretudo, da semelhança. Sendo assim, após narrar uma gama de pequenos acontecimentos cotidianos que presenciou na Abissínia, questionava:

Não se encontra em todos esses aspectos que eu cito um pouco ao acaso, um grande número de aspectos essenciais ao nosso próprio modo de vida? Eu não nego, bem entendido, que, apesar dessas analogias formais, há enormes diferenças. Mas não é humilhante para nós, que nos dizemos civilizados e pretendidos à cultura, sermos sempre antes sensíveis às diferenças e, dominados por um choque de primeira vista (...), nos apegarmos mais a elas do que às semelhanças? ${ }^{24}$

Ao final desse artigo Leiris sustentava que a "arte de viajar" era, na verdade, uma "arte do esquecimento": era preciso saber "esquecer-se das questões de pele, de odor, de gosto, e livrar-se de todo e qualquer preconceito". Menos do que acreditar no conhecimento acumulado pela civilização ocidental, era preciso livrar-se dele, reencontrar o "frescor de visão similar àquela da infância". A "arte de viajar", nessas condições, estaria, portanto, na base de "um novo humanismo", que se tornava "a cada dia mais necessário", mas que, "infelizmente, restava criar por inteiro". ${ }^{25}$

Saber viajar, estar em condições de estabelecer um "novo humanismo", era, portanto, esquecer-se de si mesmo e procurar, sobretudo, laços de identidade com outros. Para Leiris, Maurice Leenhardt ${ }^{26}$, seu amigo e professor de etnologia na École pratique des hautes études, era um exemplo de alguém que conseguia colocar-se no mesmo plano do outro. Segundo ele, em artigo publicado em 1938, ao "penetrar intimamente na sociedade canaque", vivendo em contato cotidiano com os indígenas, Leenhardt conseguira despojar-se de sua "mentalidade europeia impregnante", sem deixar de ser um excelente observador. Desse modo, no quadro que fornecia sobre a "vida 
e o pensamento" canaques, bem como nos momentos em que descrevia as mudanças desse pensamento no contato com a civilização europeia, ele jamais se esquecia do princípio que, segundo Leiris, deveria ser a "regra de ouro de todos os etnógrafos: só há conhecimento real por identificação". ${ }^{27}$

Ainda nas palavras de Leiris, Leenhardt guardava das coisas uma “visão totalizante (no sentido de 'tudo está dentro de tudo' dos ocultistas) e não dissociada, linear e mecanizada", como a que seria condicionada pelo modo de vida ocidental. ${ }^{28}$

Dez anos depois, em 1948, Michel Leiris fez uma viagem às Antilhas a convite de Aimé Césaire e com o incentivo de Alfred Métraux ${ }^{29}$. Ele faria conferências em Martinica, Guadalupe e Haiti, como parte das atividades de comemoração do centenário de Revolução de 1848 e da abolição da escravidão nas ilhas. Foi no Haiti, entretanto, que Leiris ficou mais tempo. Na companhia de Métraux, passou algumas semanas imerso no universo dos rituais de vodu. Dessa viagem resultaram, por exemplo, a conferência Message d'Afrique e o estudo Contacts de civilisation en Martinique et en Guadeloupe, publicado pela UNESCO em 1955.

Leiris iniciava Message d'Afrique, conferência pronunciada em outubro de 1948 no Instituto francês de Porto-Príncipe, contando um pouco de sua experiência pessoal, que, de acordo com ele, ajudaria na compreensão de suas sugestões. Afirmava que, na primeira vez que partira para a África, quase nada conhecia desse continente, que tinha para ele apenas "o valor de um mito". ${ }^{30}$ Contava que, até então, havia feito apenas viagens turísticas para Inglaterra, Bélgica, Holanda e Suíça. Pouco tempo depois, ainda antes de ir para a África negra, visitara o oriente próximo (Egito e Grécia) e confessava que nessa viagem, pela primeira vez, havia experimentado uma sensação de aventura e de exotismo. Entretanto, essa ainda era uma viagem pelo mediterrâneo, em lugares que aprendera, desde cedo, a considerar como "berços da civilização". Ele sentia necessidade, então, de um deslocamento - não só espacial, mas, sobretudo, cultural -, ainda mais profundo, já que, "como muitos de sua geração", sentia-se muito desconfortável na própria cultura $^{31}$ :

Cultura na qual tudo parece ter sido dito, pois chegou a certo grau de desenvolvimento técnico, mas na qual, em revanche, esse desenvolvimento apenas obteve meios de sufocar algumas das aspirações mais autênticas do Homem, como se o ganho adquirido no sentido de um domínio mais exato das coisas - ainda que muitas vezes os instrumentos que acreditamos dominar escapem a nosso controle e se voltem contra nós, de modo que nós é que nos tornamos a coisa dominada - como se o que se convencionou chamar de progresso devesse ser pago por uma estrita delimitação 
de nosso campo de atividades (...) com objetivos precisos, em detrimento de tantas sombras que nos seduzem e que, pelo encantamento que produzem em nós, poderiam tornar a vida menos difícil. ${ }^{32}$

Esse estado de espírito que não conseguia encontrar satisfação naquilo que considerava ser "o pior que poderia existir em matéria de civilização" o fizera procurar, inicialmente por meio da leitura, contato com civilizações que pareciam muito diferentes da sua, que poderiam dar acesso a outros tipos de "mentalidades" - já que a europeia, por sua vez, o "incomodava como uma roupa mal feita". Desse modo, ele não pôde negar quando surgiu a oportunidade de embarcar na Missão Dakar-Djibouti, com a finalidade de encontrar aquele continente onde se originavam tantas das coisas que amava e que lhe parecia, ao mesmo tempo, "paradisíaco e ameaçador". ${ }^{33}$

A viagem, com todos os percalços e frustrações, tivera para ele, afinal, um sentido pedagógico duplo: tanto pela aquisição objetiva (e afetiva) de conhecimento sobre outros povos, quanto pela possibilidade de enxergar o continente não mais sob o ângulo do exotismo. Uma segunda viagem à África, por sua vez, teve a função de acabar plenamente com sua ideia mitológica do continente, fazendo-o enxergar "uma África bem real, com todos os seus problemas e sofrimentos". ${ }^{34}$

$\mathrm{Na}$ África encontrara sociedades nas quais não havia separação entre os diversos planos (técnico, econômico, religioso, estético) e onde as festas misturavam arte, religião e trabalho, característica totalizante similar a das sessões de vodu nas ilhas antilhanas. Conhecera religiões que se dirigiam a forças que se podia ver e tocar, estreitamente ligadas às mais diversas atividades da vida cotidiana. Leiris denominava esses ritos de "manifestações da vida total", momentos em que o homem poderia satisfazer completamente seu desejo de plenitude - o que, nas sociedades ocidentais, "só seria possível de maneira figurada, por intermédio da ficção poética". ${ }^{35}$

O homem ocidental não era, segundo ele, mais do que um "fragmento de homem" e, nesse sentido, poderia ter muito a aprender com o "savoirvivre" africano, com sua capacidade de "contato com as coisas, de fusão com a natureza", com a capacidade de "dar presença ao concreto e à suculência imediata da vida" 36 :

Enfim, encontramos entre os africanos uma maneira de savoir-vivre, no sentido mais literal da expressão: savoir-vivre, arte da vida, modo de colocar a arte na vida, certamente inapreciável em nossa época em que o "progresso" parece decididamente ter se realizado na arte de tudo destruir, constranger e torturar. ${ }^{37}$ 
Ainda de acordo com Leiris, a etnografia ensinava que os homens eram, de modo geral, os mesmos em todos os lugares, por mais diferentes que fossem seus modos de vida. Mesmo assim, cada lugar tinha sua particularidade e revelava um modo diferente de ser homem. Nesse sentido, a sociedade africana precisava ser escutada: o "modo africano de ser homem" poderia ser um exemplo para o ocidental. O homem ocidental deveria cada vez mais, e com certa urgência, atentar para essas "manifestações de vida total", ou correria o risco de perder-se numa contínua mecanização até que não fosse mais possível qualquer relação razoável com o mundo a seu redor, com as coisas que lhe eram exteriores. ${ }^{38}$

Na conferência Antilles et poésie des Carrefours, Leiris voltaria a esse tema do aprendizado, isto é, da importância pedagógica do reconhecimento, pela civilização ocidental, de outras formas de vida e de cultura. ${ }^{39}$ Ele afirmava querer falar sobre as impressões que tivera no contato com a sociedade haitiana. Ressaltava o caráter "impressionista" de seu próprio relato, na medida em que ficara pouco tempo na região e tivera um contato apenas superficial com a população e a cultura locais. Isso poderia ser um problema, a seu ver, uma vez que, como visto, esse tipo de convívio "quase turístico" com povos de uma cultura diferente resultava, muitas vezes, na observação prioritária dos aspectos pitorescos, surpreendentes à primeira vista e, geralmente, de impacto mais estético para o olho ocidental do que, de fato, representativos dos modos de vida cotidianos. ${ }^{40}$

Sustentava, então, que as Ilhas Antilhas eram, tanto do ponto de vista estético como do ponto de vista cultural, um carrefour, ou seja, "um lugar de encontro de grupos humanos heterogêneos, e de correntes de civilização orientadas nos mais diferentes sentidos" ${ }^{\prime 4}$ :

Preciso me explicar mais a fundo sobre essa noção de carrefour - ponto de intersecção, pivô de rosa dos ventos ou cruzamento de caminhos que parecem equivaler, no domínio poético, àquilo que era o ponto fixo de que falavam os alquimistas, autêntico carrefour ele também, na medida em que se tratava, ao mesmo tempo, do lugar imutável e absoluto de onde saíam raios de forças universais e de centro único de convergência onde toda a diversidade do mundo se resolvia. ${ }^{42}$

A partir desse comentário Leiris faria uma longa digressão sobre poesia e literatura, para, finalmente, voltar às suas impressões sobre as Antilhas. Ficava claro, assim, que os dois temas se relacionavam intrinsecamente numa 
reflexão que terminava por explicitar, mais uma vez, um posicionamento ético - talvez a busca desse "novo humanismo" - do que, estritamente, os costumes dos povos antilhanos.

Leiris expunha, então, três definições do que era a beleza na poesia para, ao final, justificar o que o atraiu nas paisagens, nos modos de vida, nas práticas e nos rituais dos povos antilhanos. De acordo com ele, Baudelaire, em Écrits intimes, havia definido a beleza como a aproximação, encontro ou coincidência de duas realidades heterogêneas: uma linear, previsível (clássica); e outra, móvel, fugaz, imprevisível (moderna). De modos similares, tanto Pierre Reverdy, em seus aforismos, como André Breton teriam definido a imagem poética como o encontro dos opostos, que resultariam numa metáfora - não como comparação, mas como imagem dada, arrebatadora, criadora de novas realidades ("a beleza será convulsiva ou não será beleza", segundo Breton). ${ }^{43}$

Michel Leiris se alinhava a essa noção de beleza, assegurando que o maravilhoso da poesia era, justamente, ser um corpo insólito, estranho, mas que se apresentava tão simples como "o pão cotidiano". A beleza estaria, portanto, na associação do dos estados apolíneo e dionísiaco, que ele mesmo havia identificado, por exemplo, nos rituais das touradas, em $O$ espelho da tauromaquia, ensaio em que atestava ter tentado levar a definição de beleza de Baudelaire às últimas consequências. ${ }^{44}$

Era exatamente essa mistura de estranheza e de familiaridade, de regra e de imprevisibilidade que Leiris havia encontrado nas ilhas antilhanas, como relatava por meio de uma série de anedotas sobre a vida cotidiana da região. Entretanto, o que mais o havia emocionado foram os rituais do vodu haitiano, pois esses rituais apareciam para Leiris como uma poesia de "carne e osso", como um maravilhoso ao qual se aderia mais do que a uma ficção, como uma espécie de maravilhoso "concretizado".

Os rituais, de caráter regrado, mas abertos para a explosão dos instintos, poderiam ser comparados a uma encenação de teatro (ou às tragédias gregas). De forma diversa do "decadente teatro ocidental", no qual se dera uma definitiva separação entre atores e público, o teatro vodu configurava-se como uma arena na qual todos eram convidados a interagir, a participar dos jogos de catarse nos quais "uma longa série de dramas e comédias se sucediam", e todos os gêneros encontravam-se misturados: "violência trágica", "carrefour no qual convergiam, formando uma surpreendente unidade, os elementos mais contraditórios". ${ }^{45}$

Ele terminava a conferência, então, afirmando que seu objetivo não era fazer uma "apologia do vodu", no sentido de um elogio vazio, mas sugerir de que forma a civilização ocidental poderia aprender com essas culturas. Leiris definia-se, assim, como um homem não religioso, que apenas "buscava seu caminho" e que "amava a poesia na medida em que ela poderia refletir os grandes desejos de sua espécie", e sobre a qual ele queria encontrar sua 
"formulação própria". Angustiado com a grave conjuntura do presente europeu, num continente no qual a vida coletiva parecia ser constantemente ameaçada pelo "absurdo", era possível, talvez, tirar lições de um Haiti que havia lutado por sua liberdade e onde encontravam-se em relativa harmonia os aspectos da modernidade ocidental e da tradição africana. Onde os "aspectos apolíneo e dionisíaco da existência não poderiam ser sacrificados um ao outro sem que o próprio homem fosse também mutilado". ${ }^{46}$

A "poesia do Haiti" era, portanto, a esperança que Leiris tinha de ver se desenvolver uma civilização "menos estritamente utilitarista do que as de tipo ocidental" e em que todas as necessidades humanas, biológicas, criativas e afetivas, pudessem encontrar satisfação. ${ }^{47}$

Em 1963, Leiris foi designado para prestar uma homenagem a Alfred Métraux, que falecera naquele ano. Neste pequeno texto, ele resumia, a partir da calorosa descrição que fazia do amigo, aquilo que seria a sua própria busca como etnólogo. Ao reler os escritos de Métraux, ele constatava que, para além da importância documental, o valor de sua obra residia na "relação afetiva que se percebe sempre entre ele mesmo e aquele que ele estuda": "os lugares, assim como os homens, nunca confinados no simples papel de objetos de observação". O objeto de estudo de Métraux era visado numa perspectiva ampla, que abarcava de uma só vez toda a sua diversidade: "ele esteve sempre persuadido de que não existe observação sem que uma relação se estabeleça entre aquele que olha e aquele que é olhado". Desse modo, Métraux conseguia "ultrapassar a pura descrição científica para chegar a algo de sensível e vivo" $"$ :

Portanto, admiro em Alfred Métraux que ele tenha sido, ao mesmo tempo, observador escrupuloso (...) etnólogo consciente de todos os deveres humanos implicados por sua disciplina, e aquilo que eu posso chamar de um poeta. Entendo por poeta não somente alguém que escreve poemas, mas alguém que gostaria de chegar a uma assimilação absoluta de sua própria experiência e romper seu isolamento pela comunicação desse entendimento. Talvez Métraux tenha, paradoxalmente, chegado a uma plenitude desse gênero quando dormiu, solitário, em um lugar distante no Vallée de Chevreuse. ${ }^{49}$

James Clifford fornece algumas chaves interpretativas interessantes para se pensar os posicionamentos de Leiris. Em texto escrito sobre Bronislau Malinowski e Joseph Conrad, ele afirmou que, tanto para um quanto para outro, respectivamente em Um diário no sentido estrito do termo e Coração das trevas, a cultura, como "ficção coletiva", seria a base para a constituição da 
identidade e da liberdade individuais. Nas obras dos dois autores, guardadas suas particularidades, a busca de uma verdade própria ("own true stuff") era um produto do trabalho, "uma construção ideológica que é no entanto essencial, o fundamento da ética". ${ }^{50}$ Ou seja, para Clifford, a busca de uma verdade, de uma ética ou de uma moral, nestes autores, estava intrinsecamente vinculada à contínua construção de um self, ou uma automodelagem identitária.

Por diversas vezes Leiris declarou que só conseguia conceber a literatura como confissão. Ao longo de sua vida ele escreveu um diário (publicado postumamente) (Journal 1922-1989), e cinco livros de teor autobiográfico (ou autoetnográfico): L'âge d'Homme, e os quatros livros que compõe La Règle du jeu (Biffures, Fourbis, Fibrilles, Frêle Bruit). Pode-se afirmar que isso se configurava, para ele, como uma permanente busca de sua "own true stuff" ou uma tentativa de "assimilação absoluta da própria experiência”. Segundo as palavras do próprio Leiris, o homem ocidental só conseguiria ter acesso a lampejos dessas "manifestações de vida total" a partir da ficção poética. Buscar o que havia de mais profundamente humano - e, portanto, universal -, em si mesmo, ficcionalizar e encenar a própria vida por meio da escrita era também, então, uma busca dessa unidade perdida e uma forma de entrar "em comunhão com o outro".

Em ensaio escrito no ano de 1935 sobre a corrida espanhola ("numa perspectiva estética"), ele afirmou que um artista deveria ser um construtor de espelhos:

Incorporar a morte à vida, torná-la de certa maneira voluptuosa, tal deve ser a atividade dos construtores de espelhos, quero dizer: de todos aqueles que tem por propósito mais urgente agenciar alguns desses fatos que podemos tomar por lugares onde o homem tangencia o mundo e a si mesmo, que portanto nos alçam ao nível de uma plenitude portadora de sua própria tortura e sua própria derrisão. ${ }^{51}$

Crítico da modernidade e das prerrogativas iluministas de ciência, Michel Leiris foi, ao mesmo tempo, talvez, um produto acabado e dilacerado desse mesmo iluminismo, que trazia em si o germe de seu próprio questionamento. Em busca de uma moral e de uma ética fundada no princípio místico do "homem como microcosmo", ele viu na escrita de si e do outro, na "construção de espelhos" para a formulação do que se poderia chamar de uma etnografia da semelhança, uma forma de "romper seu isolamento" e de tornar-se verdadeiramente poeta.

\section{NOTAS}


1 Marcel Griaule fez parte de uma das primeiras gerações formadas no Instituto de Etnologia e participou das principais missões de campo no continente africano. $\mathrm{O}$ Instituto foi fundado em 1924 por Marcel Mauss, Paul Rivet e Lucien Lévy-Bhrul. O estabelecimento tinha por objetivo formar etnólogos e etnógrafos profissionais que estivessem aptos a coletar informações sobre outras culturas nos territórios coloniais franceses na África. Sobre Marcel Griaule, a missão Dakar-Djibouti e a profissionalização da etnografia na França conferir, por exemplo: BENOÎT, L'Estoile de. O arquivo total da humanidade: utopia enciclopédica e divisão do trabalho na etnologia francesa. Horizontes antropológicos, Porto Alegre, ano 9, n. 20, p. 266-302, 2003. Disponível em: <http:// www.scielo.br/pdf/ha/v9n20/v9n20a13.pdf $>$ Acesso em: 07 jun. 2014; JOLLY, Éric. Marcel Griaule, ethnologue: la construction d'une discipline (1925-1956). Journal des africanistes, Paris, tome 71, fascicule 1, p. 149-190, 2001. Disponível em:

$<$ http://www.persee.fr/web/revues/home/prescript/article/jafr_0399-0346_2001 num $71 \_1 \_1256>$

Acesso em: 07 jun. 2014; MAUSS, Marcel. L'ethnographie en France et à l'étranger. In: . Oeuvres: Cohésion sociale et divisions de la sociologie. Paris: Victor Karady, tomo. 3, 1969 .

2 Sobre o surrealismo, conferir: CHÉNIEUX-GENDRON, Jacqueline. O surrealismo. São Paulo: Martins Fontes, 1992; GUINSBURG, J.; LEIRNER, S. (Orgs). O surrealismo. São Paulo: Perspectiva, 2008; NADEAU, Maurice. História do surrealismo. São Paulo: perspectiva, 2008. Também há um artigo meu, cuja referência será adicionada posteriormente.

3 A revista Documents foi encabeçada por Georges Bataille e se estabeleceu no campo artístico francês à época como concorrente de La Révolution Surréaliste. Em Documents Bataille exercia uma contundente crítica ao surrealismo e a André Breton, que considerava um "idealista". Em oposição a um surrealismo que, supostamente, procuraria a solução para os problemas da existência "por trás do mundo" ("dérrière le monde"), Bataille propôs o "baixo materialismo". Sobre a revista Document, conferir: HOLLIER, Denis. The usevalue of the impossible. October, Massachucetts, vol. 60, p. 3-24, 1992. Disponível em: $<$ http://rae.com.pt/TC/Hollier\%20use\%20value\%20of\%20documents.pdf $>$ Acesso em: 06 jun. 2014. Sobre o projeto de Bataille em Documents conferir: DIDI-HUBERMAN, Georges. La ressemblance informe ou Le gai savoir visuel selon Georges Bataille. Paris: Macula, 1995. Sobre as discussões estabelecidas entre Bataille e Breton há um artigo meu cuja referência será adicionada aqui posteriormente. Tanto La Révolution Surréaliste quanto Documents estão disponíveis no site gallica, da BNF: $<\underline{\text { http://gallica.bnf.fr/?lang=PT> }}$ Acesso em: 06 jun. 2014.

4 Em Les deux sources de la morale et de la religion, livro publicado no ano de 1932, Henri Bergson sugeria que a mística, no século XX, teria o papel de força motriz criativa para a superação do mundo da técnica, da racionalidade e do trabalho. De fato, ao longo dos séculos XIX e XX, essa "dimensão mística" fez parte das reflexões de diversos escritores que, de alguma forma, exerceram uma atividade crítica ao universo industrial e ao do chamado homo economicus. No século XX francês, algumas correntes da mística e do gnosticismo foram extremamente importantes para a formulação dos debates tanto do surrealismo de André Breton, quanto do realismo ou baixo materialismo de Georges Bataille, e extremamente importantes para a formulação de diversos argumentos de Leiris relativos à etnografia e à literatura. Nesse sentido, Leiris fazia inúmeras referência a Hermes Trismegisto, Marsilio Ficino, Nicolau de Cusa, Paracelso, entre outros. Sobre neoplatonismo, teoria das correspondências, gnosticismo e mística conferir, por exemplo: ANDRÉ, João Maria. O 
homem como microcosmo: da concepção dinâmica do homem em Nicolau de Cusa à inflexão espiritualista da antropologia de Ficino. Philosophica, Lisboa, n. 14, p. 7-30, 1999; ANDRÉ, João Maria. Da mística renascentista à racionalidade científica pós-moderna. Revista Filosófica de Coimbra, Coimbra, n. 7, vol. 14, p. 67-101, 1995; FOUCAULT, Michel. As palavras e as coisas. São Paulo: Martins fontes, 2000; ROSSI, WILLER, Claudio Jorge. Um obscuro encanto: gnose, gnosticismo e a poesia moderna. São Paulo: Civilização brasileira, 2010; YATES, Frances A. Giordano Bruno and the hermetic tradition. London: Routledge and Kegan Paul, 1964.

5 Cf. LEIRIS, Michel. Prefácio à edição de 1951. In: . África fantasma. São Paulo: Cosac Naify, 2007, p. 47-50.

6 Em junho de 1936, Leiris obtém o certificado de História das religiões (opção: "religiões primitivas"); em novembro do mesmo ano obtém certificado na área de sociologia; em junho de 1937, obtém seu certificado de etnologia (opção: linguística e África negra); em outubro ele se torna diplomado da École nationale des langues orientales (langue amharique); em março de 1938 publica o estudo La croyance au génies zar en Éthiopie du Nord; em junho de 1938 obtém diploma da École des Hautes études (section des sciencies religieuses) com o trabalho La langue secrete des Dogons de Sanga.

7 NADEAU, op. cit, p. 18.

8 Sobre o Orientalismo surrealista conferir: THÉVENIN, Paule (Org). Archives $d u$ surréalisme: Bureau de recherches surréalistes, cahier de la permanence (octobre 1924 avril 1925). Paris: Gallimard, 1988 e JAMNIN, J.; PRICE, S. A conversation with Michel Leiris. Current Anthropology, vol. 29, n. 1, p. 157-174, fev. 1988. Disponível em:

$<$ http://www.casaruibarbosa.gov.br/arquivos/file/entrevista $\% 20$ current $\% 20$ anthropology\%20Michel\%20Leiris.pdf > Acesso em: 06 jun. 2014.

9 DAL FARRA, Maria Lucia. Surrealismo e esoterismo: a alquimia da poesia. In: GUINSBURG, J.; LEIRNER, S., op.cit, p. 741-750.

10 Apud DAL FARRA, ibidem, p. 742.

11 Apud DAL FARRA, ibidem, p. 742-743.

12 Apud DAL FARRA, ibidem, p. 747; BRETON, André. Centenaire d'Arnim. Le surréalisme au service de la Révoultion. n. 6, p. 5-9, 1933. Disponível em:

$<$ http://melusine.univ-paris3.fr/Surr au service dela Rev/Surr Service Rev6.htm> Acesso em: 06 jun. 2014.

13 LEIRIS, Michel. Notes sur deux figures microcosmiques des XIV e XV siècles. Documents : doctrines, archéologie, beaux-arts, ethnographie; n. 1, ano 1, p. 48-52, 1929.

14 Ibidem, p. 48-52.

15 Em um dos prefácios escritos para África fantasma, Leiris afirmou que decidira passar de uma "atividade quase exclusivamente literária à etnografia" porque pretendia, "ao entrar em contato com outras culturas e outras raças", "ampliar seu horizonte até uma medida verdadeiramente humana". Porém, assim concebida, a etnografia só poderia decepcionálo: "uma ciência humana permaneceria uma ciência, e a observação desinteressada não a conduziria ao contato". Cf. LEIRIS, 2007 [1951], op. cit, p. 48. Em entrevista concedida a Jean Schuster no ano de 1988 o escritor confirmaria o seu sentimento à época da missão: "a etnografia me aparecia menos como um meio de conhecimento do outro do que como um meio de contato com o outro". Cf. LEIRIS, M.; SCHUSTER, J. Entre augures. Paris: Terrain vague, 1990, p. 15-16. 
16 MAUSS, Marcel. Questões colocadas à psicologia. In: . Sociologia e Antropologia. São Paulo: Cosac Naify, 2003, p. 338-339.

17 A revista Minotaure foi dirigida pelo editor de produtos de arte Albert Skira e pelo crítico de arte E. Teriade. Eles tinham como projeto publicar uma revista dedicada à arte moderna, tomando como modelo tanto La Révolution Surréaliste quanto Documents - especialmente essa última - mas ampliando sua projeção. Minotaure foi editada entre os anos de 1933 e 1939.

18 LEIRIS, Michel. Journal (1922-1989). Paris: Gallimard, 1992 [1], p. 230.

19 LEIRIS, Michel. L’Abyssinie intime. Mer et autre mer, n. 1, p. 43-47, 1935. Reprisado em LEIRIS, Michel. Zébrage. Paris: Gallimard, 1992 [2], p. 48-56. A segunda parte da viagem na missão Dakar-Djibouti ocorreu na Etiópia (ou Abissínia, como Leiris preferia chamar a região). Tratava-se de um país independente, de modo que Leiris passou a não mais conviver intensamente com o que ele chamava de "detestáveis funcionários coloniais", e encontrou finalmente o que buscava: "quantos quilômetros foram necessários percorrer para que nos sentíssemos enfim no seio do exotismo!”. Cf. LEIRIS, 2007, op. cit.

20 LEIRIS, 1992 [2] [1935], op.cit, p. 48.

21 Ibidem, p. 49.

22 Ibidem, p. 51.

23 Ibidem, p. 52. « (...) en dépit de toutes les petits incompatibilités dont il peut s'irriter, il découvre toute une intimité, une espèce de fraternité, au moins de saine cordialité, tant il vrai que les hommes sont toujours des hommes et que, partout où il s'en trouve, il est simple de s'entendre avec eux quand il n'y a aucune raison matérielle de conflit. » (tradução minha)

24 Ibidem, p. 53-54. «Ne retrouve-t-on pas dans tous ces menus aspects que je cite à peu près au hasard un grand nombre d'aspects essentiels à notre propre mode de vie ? Je ne nie pas, bien entendu, qu'au-delà de ces analogies formelles il y ait d'énormes différences. Mais n'est-il pas humiliant pour nous, qui nous disons civilisés et prétendons à la culture, d'être avant tout sensibles aux dissemblances et, dominés par le choc de première vue, la surprise, l'inevitable dépaysement, de nous y attacher bien puls qu'aux ressemblances. » (tradução minha)

25 Ibidem, p. 56. « loin de demeurer lié aux seuls soucis de distraction ou de culture, l'art de voyager devrait être à la base d'un nouvel humanisme, qui s'avère de jour en jour plus nécessaire mais reste malheureusement tout entier à créer. » (tradução minha)

26 O pastor protestante e etnólogo Maurice Leenhardt estudou os chamados povos canaques (ou kanaks), habitantes da Nova Caledônia, parte do arquipélago da Melanésia. Na França foi professor na École pratique des hautes études e do Institut National de langues et civilisations orientales. Sobre Leenhardt ver, por exemplo: CLIFFORD, James. Person and Myth: Maurice Leenhardt in the Melanesyan world. Berkeley: University of California Press, 1982.

27 « l'auteur semble ne jamais se départir de ce principe qui devrait être le règle d'or de tous les ethnographes : il n'y a de connaisance réelle que par identificação ». LEIRIS, Michel. Gens de la grande terre. La Nouvelle Revue Française, n. 302, ano 26, 1938. Reprisado em: LEIRIS, 1992 [2], op. cit, p. 64-65. (tradução minha)

28 Ibidem, p. 65-66.

29 Alfred Métraux foi colega de Georges Bataille na École de Chartes e foi através dele que conheceu Leiris. Seguiu cursos na École pratique des hautes études e foi aluno de Marcel 
Mauss e de Paul Rivet. Estudou o vodu haitiano e diversas populações indígenas da América do Sul. Na década de 1950, tornou-se membro permanente do Departamento de ciências sociais da Unesco, onde coordenou o projeto La question raciale devant la science moderne, do qual Leiris também participou. Sobre a viagem às Antilhas, especificamente, Leiris afirmou: "Métraux e eu fomos juntos a Porto-Príncipe. (...). Ele trabalhava para a UNESCO e eu tinha ganhado uma bolsa em ocasião do centenário da Revolução de 1848. Com Métraux, nós passamos noites inteiras nas oficinas de Vodu". « Métraux et moi avions été ensemble à Port-au-Prince, j'ai dû raconter ça dans un petit text écrit lors de sa mort. Il travaillait pour l'Unesco et moi j'avais obtenu une bourse à l'occasion du centenaire de la révolution de 1848. Avec Métraux, nous passions des nuits entières dans les officines vaudou ». (tradução minha) Cf. LEIRIS, M.; SCHUSTER, J., op. cit, p. 19.

30 LEIRIS, Michel. Message de L'Afrique. In: Le Miroir de l'Afrique. Paris : Gallimard, 1996, p. 877.

31 Ibidem, p. 878

32 Ibidem, p. 878-879. « véritable malaise dans cette culture qui était la nôtre, culture où tout semble être dit parce qu'on y est parvenu à un certain degré de développement technique mais où il semble, en revanche, qu'un pareil développement n'a pu être obtenu que moyennant l'étouffement de certaines des aspirations les plus authentiques de l'homme, comme si le gain acquis dans le sens d'une domination plus exacte des choses - encore que trop souvent les instruments dont nous usons pour dominer les choses échappent à notre contrôle et se retournent contre nous de sorte que c'est nous, en fin de compte, qui devenons choses dominées - comme si ce quí'il est convenu de nommer le progrès devait nécessairement se payer pas une plus stricte délimitation du champ de nos activités, toute notre énergie se tendant vers certain buts précis, vers certaines proies bien définies, au détriment de tant d'ombres qui nous séduisaient et, par l'enchantement qu'elles exerçaient sur nous, faisaient la vie moins dificile à vivre. » (tradução minha)

33Ibidem, p. 879-880. « De cette mentalité européenne, qui me gênait comme um vêtêment mal fait, j'essayai de m'évader en lisant des ouvrages sur la mentalité 'primitif' » (tradução minha)

34 Ibidem, p. 880.

35Ibidem, p. 883-884 « Ces grands moments qui sont des manfestations de vie totale (...) des manifestations où l'homme trouve à satisfaire cette soif de plénitude que, dans nos civilisations, il ne peut guère étancher qu'au figuré, par l'intermédiaire de la fiction poétique ». (tradução minha)

36 Ibidem, p. 884.

37 Ibidem, p. 886 « Bref, nous trouvons chez les noirs africains une manière de 'savoir-vivre' au sens le plus littéral de l'expression : 'savoir-vivre', art de la vie, façon de mettre de l'art dans la vie, certainement inappréciable à notre époque où le progrès les plus nets semblent décidément s'accomplir dans l'art de détruite comme celui de contraindre ou de torturer. » (tradução minha)

38 Ibidem, p. 887.

39 LEIRIS, Michel. Antilles et poésie des carrefours. Conjonction, bulletin de l'Institut Français d'Haiti, Port-au-Prince, n. 19, février 1949, p. 1-13. (Conferência pronunciada no Instituto francês do Haiti em 25 de outubro de 1948). Texto reprisado em LEIRIS, 1992 [2], op. cit, p. 67-87.

40 Ibidem, p. 68-69. 
41 Ibidem, p. 70.

42 Ibidem, p. 71. " Il me faut m'expliquer plus à fond sur cette notion du 'carrefour', point d'intersection, pivot de rose des vents, ou croisée de chemins qui me paraît l'équivalent dans le domanie de l'expérience poétique, à ce qu 'était ce point fixe dont ont parlé les alchimistes, authentique carrefour lui aussi puisquíl s'agissait du lieu immuable et absolu d'où rayonnaient les forces universelles en même temps que du centre unique de convergence où toute la diversité du monde se résolvait » (tradução minha)

43 Ibidem, p. 72-73.

44 Ibidem, p. 73-74.

45 Ibidem, p. 82-83-84.

46 Ibidem, p. 85-86.

47 Ibidem, p. 86.

48 LEIRIS, Michel. Regards vers Alfred Métraux. In : Paris: Denoel / Gonthier, 1969, p. 134-135.

Cinq études d'ethnologie.

49 Ibidem, p. 137. « J'admire donc chez Alfred Métraux qu'il ait été, em même temps qu'un observateur scrupuleux (...), ainsi qu'un ethnologue conscient de tous les devoirs humains impliqués par sa science, ce que $\mathrm{j}$ 'appelle un poète. J'entends par là non point tellement quelqu'un qui écrit des poèmes, mais quelqu'un qui voudrait parvenir à une absolue saisie de ce en quoi il vit et à rompre son isolement par la communication de cette saisie. Peutêtre Alfred Métraux a-t-il atteint, paradoxalement, une plénitude de ce genre quand il s'est endormi, tout seul, dans un lieu retiré de la vallée de Chevreuse. » (tradução minha)

50 CLIFFORD, James. Sobre a automodelagem etnográfica: Conrad e Malinowski. In: GONÇALVES, José Reginaldo Santos (Org). A experiência etnográfica. Rio de Janeiro: Editora UFRJ, 2011, p. 109.

51 LEIRIS, Michel. O espelho da Tauromaquia. São Paulo: Cosac Naify, 2001, p. 75.

Artigo recebido em abril de 2015. Aceito em dezembro de 2015. 